\title{
Analysis and Design of Bandpass Single-Pole-Double-Throw FET Filter-Integrated Switches
}

\author{
Zuo-Min Tsai, Member, IEEE, Yu-Sian Jiang, Jeffrey Lee, Student Member, IEEE, Kun-You Lin, Member, IEEE, \\ and Huei Wang, Fellow, IEEE
}

\begin{abstract}
This paper proposes a method to integrate a single-pole-double-throw (SPDT) switch and a quarter-wavelength bandpass filter. A 1-GHz SPDT hybrid switch and a 60-GHz pseudomorphic HEMT monolithic-microwave integrated-circuit SPDT switch with $30 \%$ fractional bandwidth are demonstrated. The 1-GHz SPDT switch achieves 1.5-dB insertion loss and 20-dB isolation at center frequency. For the $60-\mathbf{G H z}$ SPDT switch, the measured insertion loss is lower than $2.5 \mathrm{~dB}$ and the isolation is higher than $27 \mathrm{~dB}$. The low insertion loss and high isolation show that no performance is degraded when integrating the filter function. The analysis of the power performance is also described. Using the device dc- $I V$ curves, the power compression point can be predicted.
\end{abstract}

Index Terms-Bandpass filter, monolithic microwave integrated circuit (MMIC), power compression point, single-pole double-throw (SPDT).

\section{INTRODUCTION}

$\mathbf{R}$ ADIO-FREQUENCY (RF) switches are important in time division duplex wireless communication systems. Since a filter is required in front of a switch when integrating a wireless system, the integration of filter and switch functions has the advantages of reduction of insertion loss, as well as complexity. To achieve good switching performance, the nonideal off-state capacitance and on-state resistance need to be taken into considerations. In [1], the nonideal effects of the device are first applied for the $2.69-\mathrm{GHz}$ ring-filter integrated with a single-pole-single-throw (SPST) switch. In [2], the concept of the filter-integrated switch (FIS), which gives the systematic design approach to implement the switch using the filter synthesis of a 1-GHz quarter-wavelength bandpass filter, was proposed.

To design a single-pole-double-throw (SPDT) switch, an impedance transformer is usually required to combine two SPST switches so that the impedance of the off-state SPST switch will not influence the insertion loss of the on-state SPST switch [3], [4], [7], [8] in cases when the input/output

Manuscript received November 14, 2006; revised March 21, 2007. This work was supported in part by the National Science Council of Taiwan, R.O.C., under Grant NSC 93-2752-E-002-002-PAE, Grant NSC 93-2219-E-002-016, Grant NSC 93-2219-E-002-024, and Grant NSC 93-2213-E-002-033 and by National Taiwan University under Excellent Research Project 95R0062-AE00-01.

The authors are with the Graduate Institute of Communication Engineering and the Department of Electrical Engineering, National Taiwan University, Taipei, Taiwan 10617, R.O.C. (e-mail: hueiwang@ntu.edu.tw; kunyou@ntu.edu.tw).

Digital Object Identifier 10.1109/TMTT.2007.901132 impedances of off-state switches are low. In [3], the image filter synthesis was applied in the design of an SPST traveling-wave switch and quarter-wavelength transmission lines applied as an impedance transformer. However, the frequency response of the entire SPDT switch cannot be synthesized. In [12], a narrowband hybrid SPDT switch using diodes with integration of a coupled-resonator filter was demonstrated by the shared resonator technique. The hybrid switch exhibits $5 \%$ fractional bandwidth (FBW) because of the filter topology. However, the topology in [12] is not suitable for wide-bandwidth application.

In this paper, we expand the concept of field-effect transistor (FET) FISs from SPST [2] to SPDT switches. The quarter-wavelength impedance transformers are integrated in the quarter-wavelength bandpass filter. A $1-\mathrm{GHz}$ hybrid and a $60-\mathrm{GHz}$ monolithic-microwave integrated-circuit (MMIC) SPDT switches are both implemented to verify the design concept. The SPDT switches exhibit 30\% FBW and are suitable for the wide-bandwidth communication system. A simple and general analysis of the power compression is also described. The analysis in [2] is only derived for SPST switches. On the other hand, a more general analysis for $n$-port passive nonlinear circuits is proposed here. This analysis can not only be applied to this SPDT switch, but also to other $n$-port passive switches.

\section{CONCEPT OF SPDT FIS}

The concept of the SPST FIS has been proposed in [2]. To implement an SPDT FIS, the impedance of the off-state SPST switch and the impedance transformer that combines two SPST switches have to be designed as part of the filter. Fig. 1(a) illustrates the circuit block diagram of the conventional SPDT switch. It is composed of two SPST switches and one impedance transformer. For the shunt switch, quarter-wavelength transformers are used to transfer the low impedance of the off-state SPST switch to high impedance [4]. Although the filter analysis was used in the low-pass SPST switch design, the frequency responses of the entire SPDT switch were not synthesized due to the bandpass impedance transformer. However, in our proposed filter-integrated SPDT switch, the impedance transformer and the SPST switches are designed for bandpass frequency response, as shown in Fig. 1(b).

Fig. 2(a) shows the circuit schematic of the SPDT FIS. It is composed of five shunted resonators and four series quarterwavelength transmission lines. One short stub shunted resonator directly connects to Port 1 . Other four shunted resonators are constructed by parallel transistors and short stubs. 


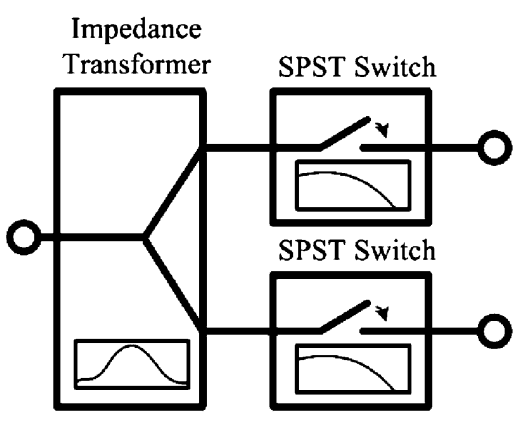

(a)

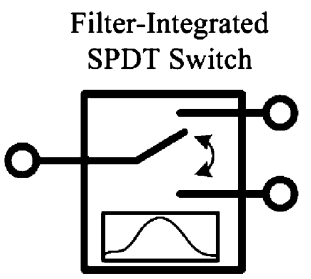

(b)

Fig. 1. (a) Circuit block diagram of conventional SPDT switches. (b) Concept of the filter-integrated SPDT switch.

Fig. 2(b) illustrates the equivalent circuit of the SPDT switch when $V_{\mathrm{c} 1}$ is below the threshold voltage and $V_{\mathrm{c} 2}$ is higher than the threshold voltage. Since $V_{\mathrm{c} 1}$ is below the threshold voltage, the transistors are turned off and can be modeled to capacitors $\left(C_{\text {off1 }}\right.$ and $\left.C_{\text {off2 }}\right)$. Similarly, the high $V_{\mathrm{c} 2}$ turned on the transistors and the transistors are modeled as resistors $\left(G_{\mathrm{on} 1}\right.$ and $\left.G_{\mathrm{on} 2}\right)$. Comparing Fig. 2(b) and (c), we can treat the through path of the SPDT switch (Port 2 to Port 1) as the third-order quarter-wavelength short-circuited stubs bandpass filter shown in Fig. 2(c). To make the frequency response of the third-order quarter-wavelength short stubs bandpass filter equal to the through path of the SPDT switch, two series quarter-wavelength transmission lines between Port 1 and Port 2 in Fig. 2(b) correspond to the series transmission lines in Fig. 2(c). Furthermore, the susceptance and their frequency derivatives at the center frequency $\omega_{0}$ of three shunt resonators ( $Y_{\mathrm{R} 1}, Y_{\mathrm{R} 2}$, and $Y_{\mathrm{R} 3}$ ) of the switch have to be identical to those of the bandpass filter $\left(Y_{\mathrm{Rf} 1}, Y_{\mathrm{Rf} 2}\right.$, and $\left.Y_{\mathrm{Rf} 3}\right)$. Thus, the relation of the design parameters between the switch and bandpass filter can be obtained as

$$
\begin{aligned}
& \operatorname{Im}\left(Y_{\mathrm{R} 1}\right)=\operatorname{Im}\left(Y_{\mathrm{Rf} 1}\right)=\omega_{0} C_{\text {off } 1}-Y_{1} \cot \theta_{1}=0 \\
& \operatorname{Im}\left(Y_{\mathrm{R} 2}\right)=\operatorname{Im}\left(Y_{\mathrm{Rf} 2}\right)=\omega_{0} C_{\text {off } 2}-Y_{2} \cot \theta_{2}=0 \\
& \operatorname{Im}\left(Y_{\mathrm{R} 3}\right)=\operatorname{Im}\left(Y_{\mathrm{Rf} 3}\right)=\operatorname{Im}\left(Y_{12}^{2} / Y_{\text {iso }}-j Y_{3} \cot \theta_{3}\right)=0 .
\end{aligned}
$$

In (3), $Y_{\text {iso }}$ is the admittance from the turned-on transistor to the isolation port and is expressed with the system characteristic admittance $Y_{0}$. Since the transistors are turned on, $G_{\text {on2 }}$ and $G_{\mathrm{on} 1}$ are large conductances, and thus, it is reasonable to approximate $Y_{\text {iso }}$ to $G_{\text {on2 }}$ as follows:

$$
\begin{aligned}
Y_{\text {iso }} & =G_{\text {on } 2}-j Y_{2} \cot \theta_{2}+\frac{Y_{12}^{2}}{Y_{0}+G_{\text {on } 1}-j Y_{1} \cot \theta_{1}} \\
& \cong G_{\text {on } 2} .
\end{aligned}
$$

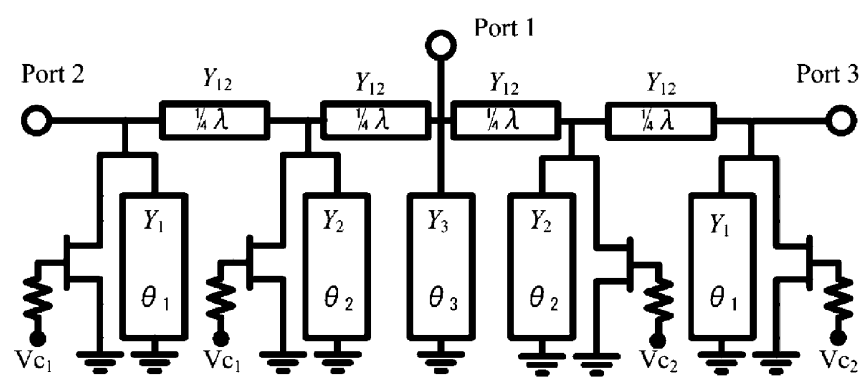

(a)

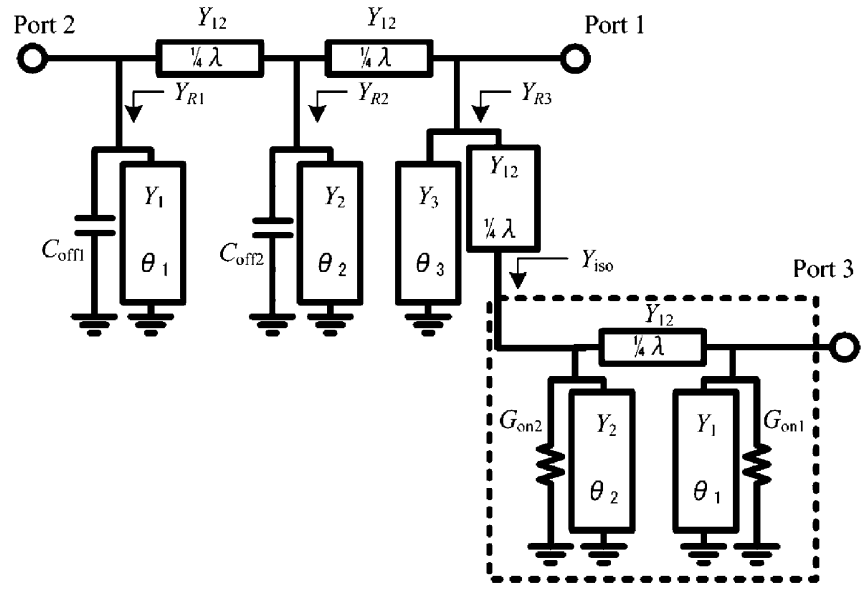

(b)

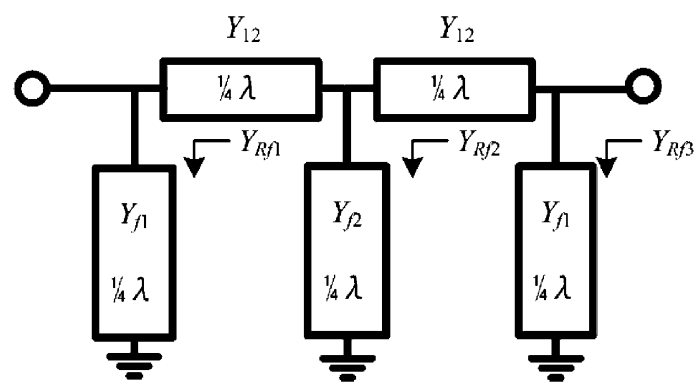

(c)

Fig. 2. (a) Proposed SPDT FIS. (b) Equivalent circuit of the SPDT switch. (c) Circuit schematic of a third-order quarter-wavelength short-circuited stubs bandpass filter.

Since the frequency derivatives of the susceptances should be equal, we can obtain

$$
\begin{aligned}
Y_{\text {Rf1 } \frac{\pi}{4 \omega_{0}}} & =C_{\text {off } 1}+\frac{Y_{1} \theta_{1}}{\omega_{0}} \csc ^{2} \theta_{1} \\
Y_{\text {Rf } 2} \frac{\pi}{4 \omega_{0}} & =C_{\text {off2 }}+\frac{Y_{2} \theta_{2}}{\omega_{0}} \csc ^{2} \theta_{2} \\
Y_{\text {Rf3 } \frac{\pi}{4 \omega_{0}}} & =\frac{Y_{3} \theta_{3}}{\omega_{0}} \csc ^{2} \theta_{3}-\frac{\pi Y_{12}\left(G_{\text {on2 } 2}^{2}-Y_{12}^{2}\right)}{2 \omega_{0} G_{\text {on } 2}^{2}} .
\end{aligned}
$$

Applying the filter synthesis, the design parameters of the bandpass filter $\left(Y_{12}, Y_{\mathrm{Rf} 1}, Y_{\mathrm{Rf} 2}\right.$, and $\left.Y_{\mathrm{Rf} 3}\right)$ can be obtained. With given device size, $C_{\mathrm{off} 1}, C_{\mathrm{off} 2}, C_{\mathrm{off} 3}, G_{\mathrm{on} 1}$, and $G_{\mathrm{on} 2}$ are determined. Consequently, the design parameters of the switch $\left(Y_{12}, Y_{1}, Y_{2}, Y_{3}, \theta_{1}, \theta_{2}\right.$, and $\left.\theta_{3}\right)$ are obtained from (1)-(7).

For the insertion loss of the through path at $\omega_{0}$, only one lossy component $G_{\mathrm{on} 2}$ is required to be taken into consideration. From (1) to (3), $Y_{\mathrm{R} 1}, Y_{\mathrm{R} 2}$, and $Y_{\mathrm{R} 3}$ are all zero at $\omega_{0}$, the 


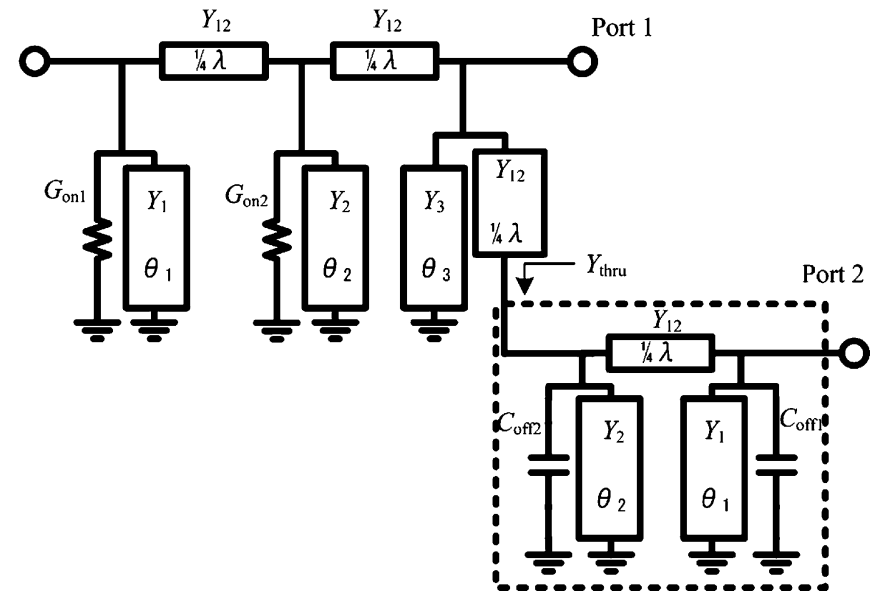

Fig. 3. Circuit schematic for the calculation of isolation.

insertion loss $S_{21}$ is expressed in terms of $Y_{12}, Y_{0}$, and $G_{\mathrm{on} 2}$ as follows:

$$
S_{21}=-\frac{Y_{0}}{Y_{0}+\frac{Y_{12}^{2}}{2 G_{\text {on } 2}}-j \frac{Y_{3} \cot \theta_{3}}{2}} .
$$

Similarly, the isolation of the isolation path can be calculated. From Fig. 3, the input admittance from the off-state transistor $\left(Y_{\text {thru }}\right)$ to Port 2 is expressed as

$$
Y_{\mathrm{thru}}=-Y_{12}^{2} / Y_{0}
$$

From (9), the isolation $S_{31}$ is (10), shown at the bottom of this page.

From (8) and (10), it is observed that the insertion loss and isolation can be improved by increasing $G_{\mathrm{on} 1}$ and $G_{\mathrm{on} 2}$. It is also noticed that both the insertion loss and isolation can be improved at the same time. One constraint is that $C_{\text {off1 }}$ and $C_{\text {off2 }}$ have to be in a reasonable range to make (1)-(7) solvable. Since $G_{\text {on1 } 1}, G_{\text {on2 } 2}, C_{\text {off1 }}$, and $C_{\text {off2 } 2}$ are the on-state channel conductances and off-state capacitances of the transistor and are all proportional to the gatewidth of the device, the device sizes in the switch need to be selected to make (1)-(7) solvable.

It is worth mentioning that in the conventional switch design, there are tradeoffs between insertion loss and the isolation for the device size. Due to the off-state capacitance, the insertion loss will be higher if the device size is increasing. However, in our new approach, the off-state capacitance is one of the design parameters and is to be resonated with the short stubs. Furthermore, by adjusting the impedance and length of the short stubs, both the susceptance and frequency differentiation of the susceptance can be equal to those of the quarter-wavelength bandpass filter and, thus, the frequency response of the switch may be synthesized.

\section{Power ANALysis}

There are two steps to analyze the power performance. The first step is to describe the nonlinear device, and the second is to define the relation between power compression and the nonlinear conductance. In [2], the relation between power compression and the nonlinear conductance was derived only for the SPST FIS, but is not suitable for SPDT switches. To analyze our SPDT switches, a more general analysis is performed for an arbitrary $n$-port network. Thus, this method is not only suitable for this SPDT switches, but also for $n$-port passive switches.

It is noticed that the piecewise linear approximation is used for the power analysis, which can estimate the power handling of the circuit fairly accurately. However, the piecewise linear approximation cannot be used to estimate the intermodulation since the third-order nonlinear effect is needed in the calculation of the intermodulation.

\section{A. Piecewise Linear Approximation}

Fig. 4(a) illustrates the measured $I V$ curves of the off-state passive HEMT [13]. By approximating the $I V$ curves with two segments, $I_{\mathrm{ds}}$ can be expressed as

$$
I_{\mathrm{ds}}=\left\{\begin{array}{l}
0, \quad \text { if } V_{\mathrm{ds}}>-V_{x} \\
G_{x}\left(V_{\mathrm{ds}}+V_{x}\right), \quad \text { if } V_{\mathrm{ds}} \leq-V_{x} .
\end{array}\right.
$$

Assuming $V_{\mathrm{ds}}$ is a sinusoid voltage signal,

$$
V_{\mathrm{ds}}=V_{p} \cos \omega t .
$$

The amplitude of the fundamental term of $I_{\mathrm{ds}}$ can be evaluated by the Fourier transformation

$$
I_{\mathrm{ds}}=\frac{G_{x}}{\pi}\left(\frac{V_{p}}{2}(2 \phi+\sin 2 \phi)-2 V_{x} \sin \phi\right) .
$$

In (13), $\phi$ is the conduction angle and is defined as

$$
\phi=\cos ^{-1}\left(\frac{V_{x}}{V_{p}}\right) .
$$

From (13), the nonlinear conductance of the off-state transistor $\left(G_{\mathrm{off}}^{\mathrm{nl}}\right)$ can be expressed in terms of $G_{x}, \theta$, and $V_{p}$ as follows:

$$
G_{\mathrm{off}}^{\mathrm{nl}}=\left\{\begin{array}{c}
0, \quad \text { if } V_{x}>V_{p} \\
G_{x}\left(\frac{(2 \phi-\sin 2 \phi)}{2 \pi}\right), \quad \text { if } V_{x} \leq V_{p} .
\end{array}\right.
$$

$$
\left.S_{31}=-\frac{2 Y_{0}}{+\left(\begin{array}{l}
G_{\text {on } 1}+Y_{0}-j Y_{1} \cot \theta_{1} \\
\left.\frac{\left(2 Y_{0}-j Y_{3} \cot \theta_{3}\right)}{2}+\left(G_{\text {on }}+Y_{0}-j Y_{1} \cot \theta_{1}\right)\left(G_{\text {on } 2}-j Y_{2} \cot \theta_{2}\right)\right)
\end{array}\right)}\right)
$$




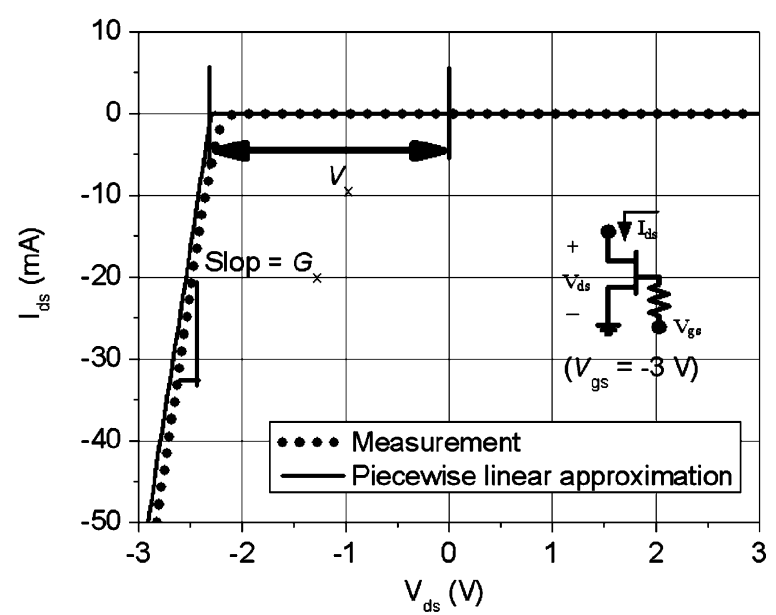

(a)

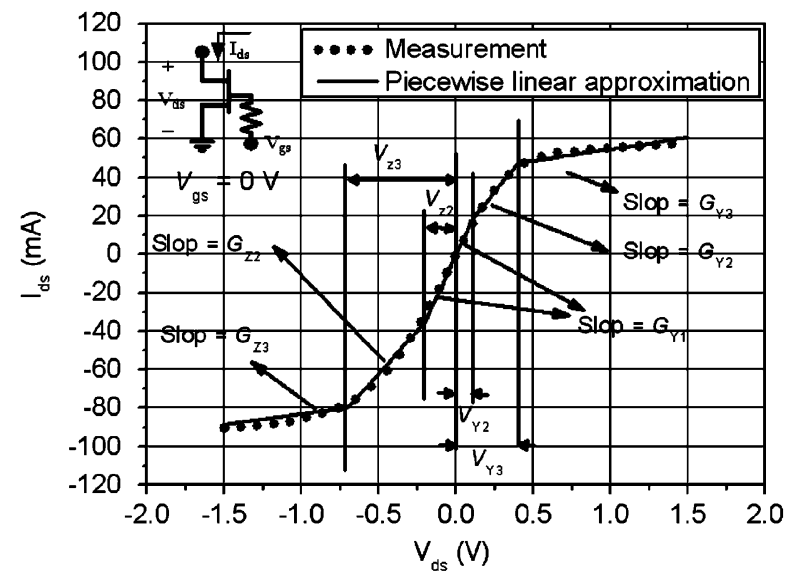

(b)

Fig. 4. Measured and piecewise linear approximation of the FET (NE32584C [13]) in: (a) turned-off state and (b) turned-on state.

For the measured on-state passive HEMT shown in Fig. 4(b), the $I V$ curves of the on-state transistor can be expressed as

$$
I_{\mathrm{ds}}=\left\{\begin{array}{l}
G_{y 1} V_{\mathrm{ds}}, \quad \text { if }-V_{z 1}<V_{\mathrm{ds}}<V_{y 1} \\
G_{y 2} V_{\mathrm{ds}}+\left(G_{y 1}-G_{y 2}\right) V_{y 1}, \quad \text { if } V_{y 1} \leq V_{\mathrm{ds}}<V_{y 2} \\
G_{y 3} V_{\mathrm{ds}}+\left(G_{y 2}-G_{y 3}\right) V_{y 2}+\left(G_{y 1}-G_{y 2}\right) V_{y 1}, \\
\quad \text { if } V_{\mathrm{ds}}>V_{y 2} \\
G_{z 2} V_{\mathrm{ds}}+\left(G_{y 1}-G_{z 2}\right) V_{z 1}, \\
\quad \text { if }-V_{z 1}>V_{\mathrm{ds}} \geq-V_{z 2} \\
G_{z 3} V_{\mathrm{ds}}+\left(G_{z 2}-G_{z 3}\right) V_{z 2}+\left(G_{y 1}-G_{z 2}\right) V_{z 1}, \\
\quad \text { if } V_{\mathrm{ds}}<-V_{z 2} .
\end{array}\right.
$$

Therefore, the nonlinear conductance of the on-state transistor $\left(G_{\mathrm{on}}^{\mathrm{nl}}\right)$ is derived as

$$
\begin{aligned}
& G_{\mathrm{on}}^{\mathrm{nl}} \\
& =\left\{G_{y 1}+\frac{1}{\pi}\left(\begin{array}{c}
\left(G_{y 2}-G_{y 1}\right)\left(\phi_{y 1}-\cos \phi_{y 1} \sin \phi_{y 1}\right) \\
+\left(G_{y 3}-G_{y 2}\right)\left(\phi_{y 2}-\cos \phi_{y 2} \sin \phi_{y 2}\right) \\
+\left(G_{z 2}-G_{y 1}\right)\left(\phi_{z 1}-\cos \phi_{z 1} \sin \phi_{z 1}\right) \\
+\left(G_{z 3}-G_{z 2}\right)\left(\phi_{z 2}-\cos \phi_{z 2} \sin \phi_{z 2}\right)
\end{array}\right) .\right.
\end{aligned}
$$

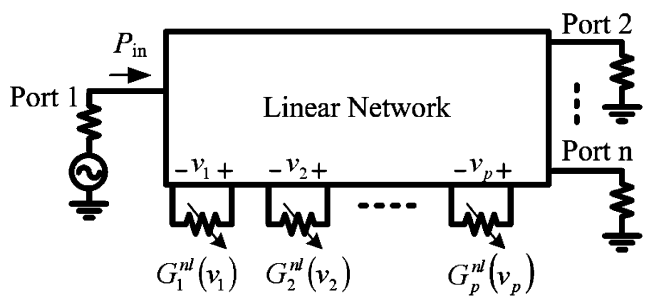

Fig. 5. Schematic of a general $n$-port nonlinear circuit with driving power source.

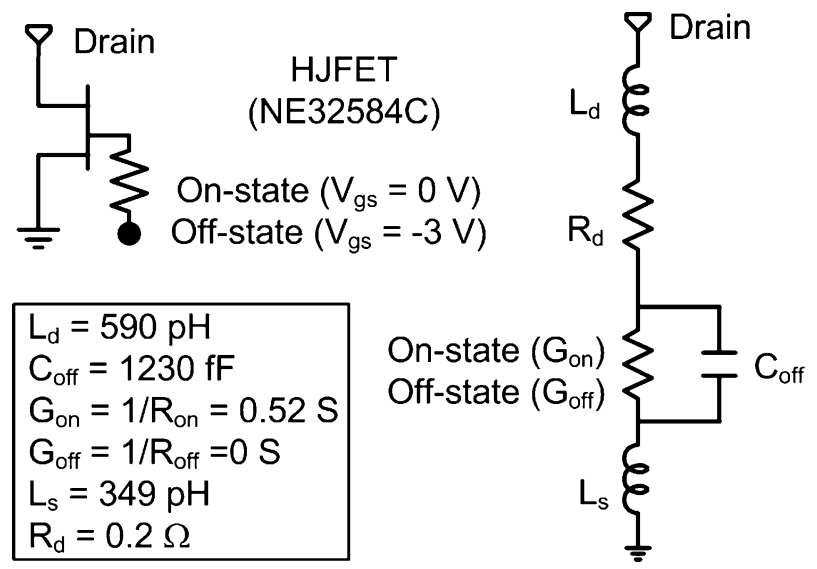

Fig. 6. Simplified passive HEMT small-signal model of NE32584C.

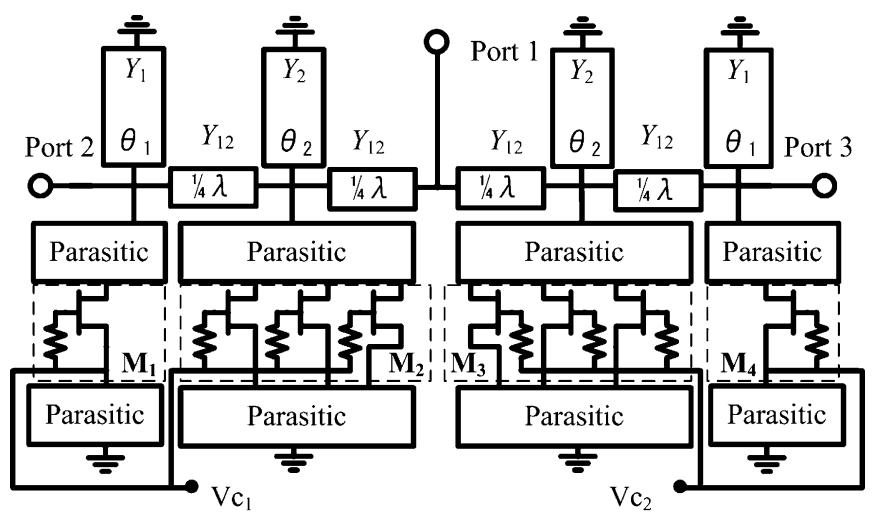

Fig. 7. Circuit schematic of the 1-GHz hybrid SPDT switch.

In (14), $\phi_{y 1}, \phi_{y 2}, \phi_{z 1}$, and $\phi_{z 2}$ are defined as

$$
\begin{aligned}
& \phi_{y 1}= \begin{cases}\cos ^{-1}\left|V_{y 1} / V_{p}\right|, & \text { if } V_{y 1}<V_{p} \\
0, & \text { if } V_{y 1} \geq V_{p}\end{cases} \\
& \phi_{y 2}= \begin{cases}\cos ^{-1}\left|V_{y 2} / V_{p}\right|, & \text { if } V_{y 2}<V_{p} \\
0, & \text { if } V_{y 2} \geq V_{p}\end{cases} \\
& \phi_{z 1}= \begin{cases}\cos ^{-1}\left|V_{z 1} / V_{p}\right|, & \text { if } V_{z 1}<V_{p} \\
0, & \text { if } V_{z 1} \geq V_{p}\end{cases} \\
& \phi_{z 2}= \begin{cases}\cos ^{-1}\left|V_{z 2} / V_{p}\right|, & \text { if } V_{z 2}<V_{p} \\
0, & \text { if } V_{z 2} \geq V_{p} .\end{cases}
\end{aligned}
$$

With the piecewise linear parameters and the implementation of (15) and (17), the relation between voltage amplitude and the equivalent admittance $\left(G_{\mathrm{off}}^{\mathrm{nl}}\right.$ and $\left.G_{\mathrm{on}}^{\mathrm{nl}}\right)$ can be analytically evaluated.

\section{B. Analysis of the Power Compression}

Fig. 5 illustrates the general schematic of an $n$-port nonlinear circuit with power source $\left(P_{\text {in }}\right)$ driving to Port 1 . The 


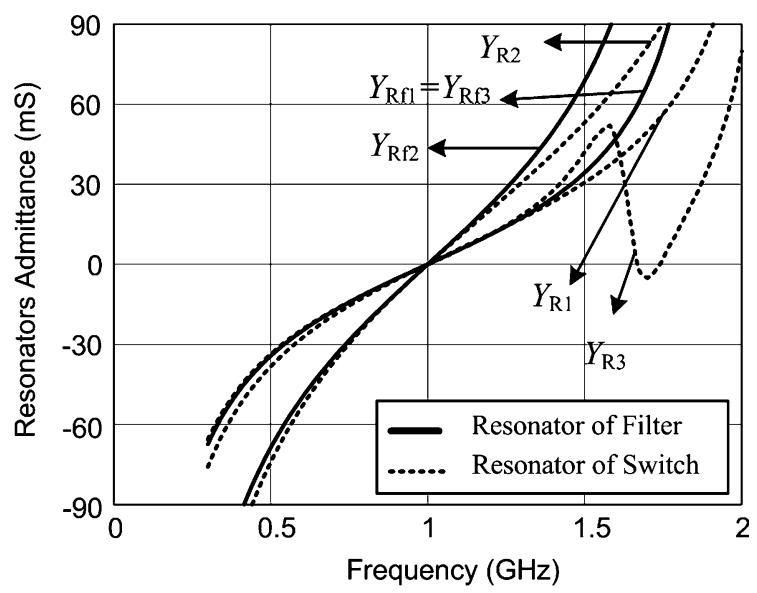

Fig. 8. Admittance of the resonator of filter $\left(Y_{\mathrm{Rf} 1}, Y_{\mathrm{Rf} 2}\right.$, and $\left.Y_{\mathrm{Rf} 3}\right)$ and resonator of switch $\left(Y_{\mathrm{R} 1}, Y_{\mathrm{R} 2}\right.$, and $\left.Y_{\mathrm{R} 3}\right)$.

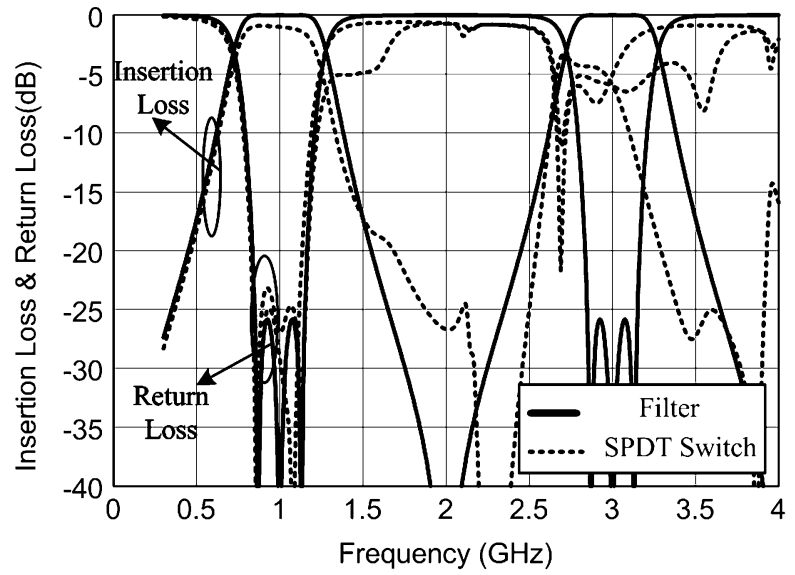

Fig. 9. Comparison of the simulated frequency responses between the 1-GHz ideal third-order filter and the 1-GHz hybrid SPDT switch.

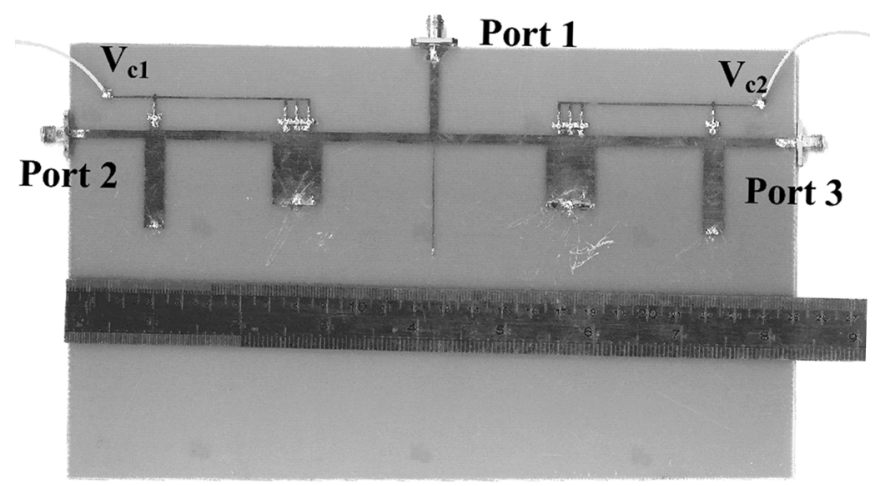

Fig. 10. 1-GHz hybrid SPDT switch.

schematic is composed of one linear network and several nonlinear conductances $\left(G_{1}^{\mathrm{nl}} \sim G_{n}^{\mathrm{nl}}\right)$. The nonlinear conductance are assumed to be constants when the voltage swings $\left(v_{1} \sim v_{p}\right)$ are small, and after the voltage swings become large, the components are driven into the nonlinear region since $\left(G_{1}^{\mathrm{nl}} \sim G_{p}^{\mathrm{nl}}\right)$ are weakly nonlinear at the input $x$-dB compression point $\left(P_{x \mathrm{~dB}}, 0<x \leq 1\right)$. The effect of $\left(G_{1}^{\mathrm{nl}} \sim G_{p}^{\mathrm{nl}}\right)$ can be discussed separately. Considering only $G_{1}^{\mathrm{nl}}, G_{1}^{\mathrm{nl}}$ input,

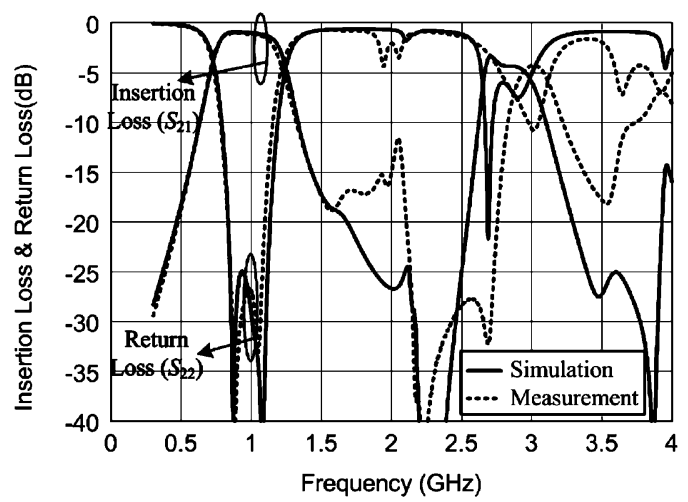

(a)

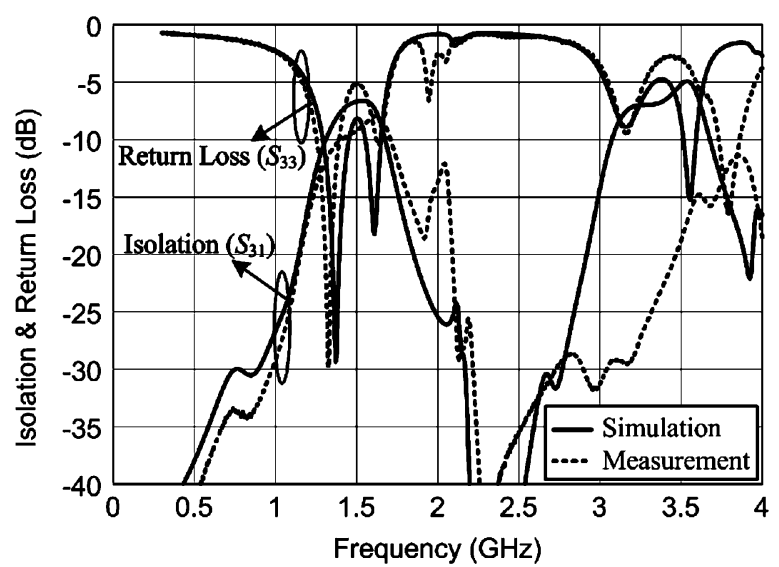

(b)

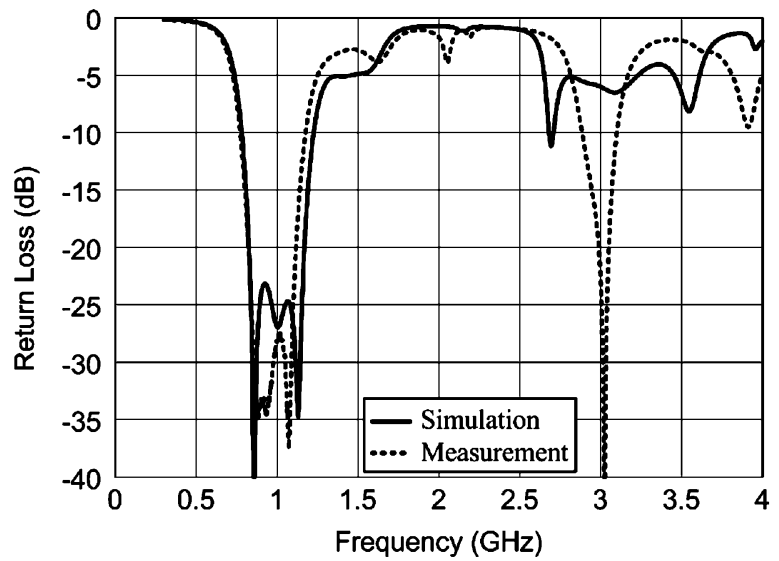

(c)

Fig. 11. Simulated and measured results of the 1-GHz hybrid SPDT switch. (a) Insertion loss and output return loss of the on-state switch. (b) Isolation and output return loss of the off-state switch. (c) Input return of the switch.

$P_{x \mathrm{~dB}}$ can be obtained by sweeping $G_{1}^{\mathrm{nl}}$ for the $n$-port network parameters $\left(S_{\mathrm{mn}}\left(G_{1}^{\mathrm{nl}}\right)\right)$ since $G_{1}^{\mathrm{nl}}$ is the function of $v_{1}$, while $v_{1}$ is also a function of $P_{\text {in }}, P_{\text {in }}$ at $x$ - $\mathrm{dB}$ compression dominated by $G_{1}^{n}$ can be determined. After investigating the conductance one by one, the input $P_{x \mathrm{~dB}}$ of the $n$-port nonlinear circuit can be determined by the lowest $x$ - $\mathrm{dB}$ compression point and the dominant nonlinear conductance can be decided.

It is worth noticing that no nonlinear simulation tool is used to find the $x$-dB compression point in this method. For the passive HEMT, the nonlinear effect of the $\left(G_{1}^{\mathrm{nl}} \sim G_{p}^{\mathrm{nl}}\right)$ is analyt- 
TABLE I

Device Parameters of the Device Obtained in Piecewise LINEAR APPROXIMATION (NE32584C)

\begin{tabular}{cc}
\hline \hline Parameters & Value \\
\hline$V_{\mathrm{x}}(\mathrm{V})$ & 2.3 \\
$V_{\mathrm{y} 1}(\mathrm{~V})$ & 0.1 \\
$V_{\mathrm{y} 2}(\mathrm{~V})$ & 0.4 \\
$V_{\mathrm{y} 1}(\mathrm{~V})$ & 0.2 \\
$V_{\mathrm{y} 2}(\mathrm{~V})$ & 0.7 \\
& \\
\hline \hline
\end{tabular}

\begin{tabular}{cc}
\hline \hline Parameters & Value \\
\hline$G_{\mathrm{x}}(\mathrm{mS})$ & 81.9 \\
$G_{\mathrm{y} 1}(\mathrm{mS})$ & 175 \\
$G_{\mathrm{y} 2}(\mathrm{mS})$ & 100 \\
$G_{\mathrm{y} 3}(\mathrm{mS})$ & 12 \\
$G_{\mathrm{y} 2}(\mathrm{mS})$ & 90 \\
$G_{\mathrm{y} 3}(\mathrm{mS})$ & 11 \\
\hline \hline
\end{tabular}

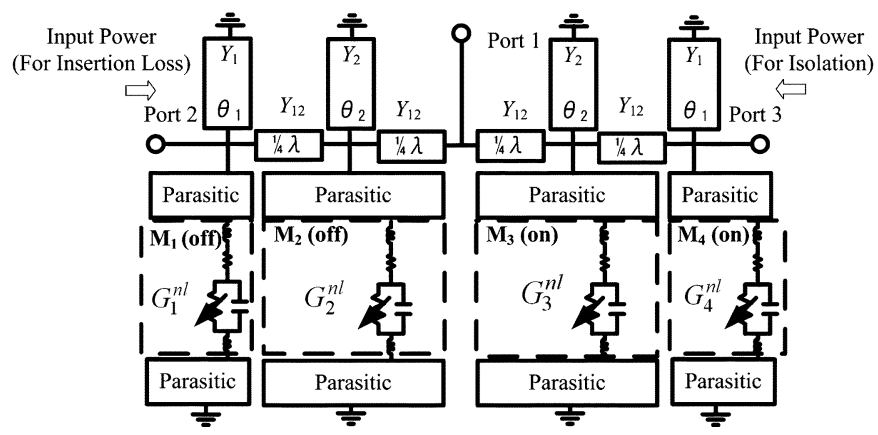

Fig. 12. Schematic of the 1-GHz SPDT hybrid switch for power analysis.

ically expressed in (15) and (17). Thus, only the $I V$ curves and linear network analysis tool are required to obtain the power performance.

\section{EXPERIMENTAL RESULTS}

\section{A. 1-GHz Hybrid SPDT Switch}

The devices used for this experiment are a packaged heterojunction field-effect transistor (HJFET) (NE32584C [13]). Fig. 6 illustrates the simplified passive HEMT small-signal model [4] of NE32584C. When the gate voltage changes from -3 to $0 \mathrm{~V}$, the passive HEMT is switched from the off to the on state and has $0.52-\mathrm{S}$ channel conductance $\left(G_{\text {on }}\right)$. Fig. 7 shows the complete circuit schematic of the 1-GHz SPDT switch. This switch is realized on an FR4 printed circuit board (PCB) board. From (8), it can be observed that the insertion loss is dominated by the turn-on conductance of $\mathrm{M}_{3}$. Therefore, the three-paralleled devices are selected as $M_{2}$ and $M_{3}$ to reduce the turn-on conductance from 0.52 to $0.17 \mathrm{~S}$.

The SPDT switch is designed for $1-\mathrm{GHz}$ center frequency, $30 \% \mathrm{FBW}$, and $0.01-\mathrm{dB}$ equal ripple frequency response. In the filter synthesis, the parameters of the filter prototype in Fig. 2(c) and the parameter $Y_{12}$ are determined. Based on the design equations (1)-(3) and (5)-(7), the admittance and frequency derivatives of each shunt resonator $\left(Y_{\mathrm{R} 1}, Y_{\mathrm{R} 2}\right.$, and $\left.Y_{\mathrm{R} 3}\right)$ have to be equal to those of a third-order quarter-wavelength bandpass filter $\left(Y_{\mathrm{Rf} 1}, Y_{\mathrm{Rf} 2}\right.$, and $\left.Y_{\mathrm{Rf} 3}\right)$ and, thus, the parameters $Y_{1}, Y_{2}$, and $Y_{3}$ can be determined. Fig. 8 shows the admittance of the resonators $\left(Y_{\mathrm{Rf} 1}, Y_{\mathrm{Rf} 2}\right.$, and $\left.Y_{\mathrm{Rf} 3}\right)$ and those of the switches $\left(Y_{\mathrm{R} 1}, Y_{\mathrm{R} 2}\right.$, and $\left.Y_{\mathrm{R} 3}\right)$ versus frequency. It can be observed that admittance of the resonators of the switch are close to those of the filter when the frequency is lower than $1.3 \mathrm{GHz}$ so that the conditions in (1)-(3) and (5)-(7) are satisfied.

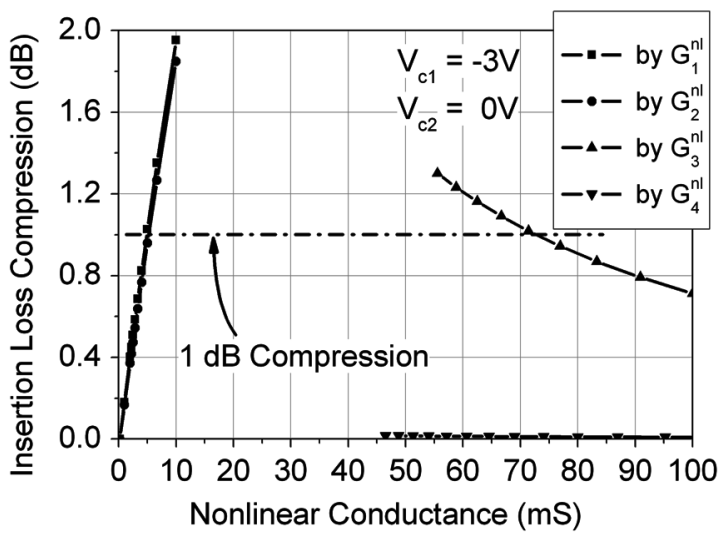

(a)

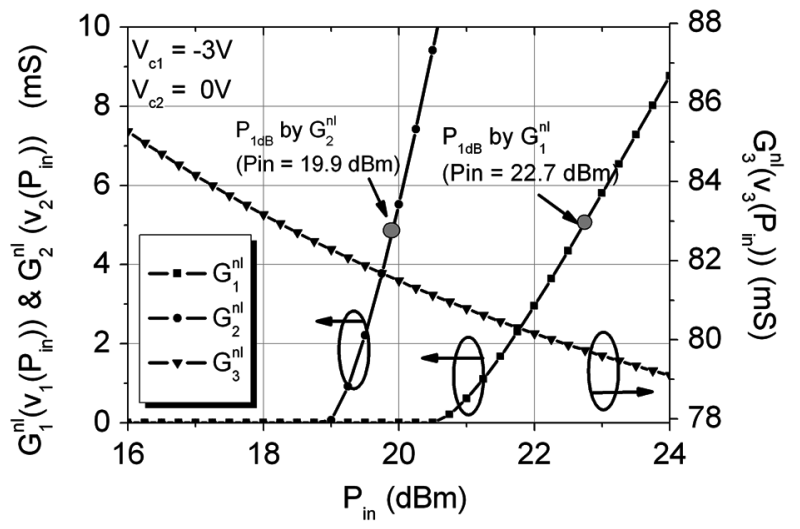

(b)

Fig. 13. (a) Compression of Port 2 to Port 1 insertion loss versus nonlinear conductances of 1-GHz SPDT hybrid switch. (b) Calculated nonlinear conductance versus input power $\left(P_{\text {in }}\right)$ at Port 2 of 1-GHz SPDT hybrid switch.

In this 1-GHz circuit design, the parasites in the package and layout discontinuities are taken into consideration. Fig. 9 shows the frequency responses of the ideal third-order bandpass filter and those of the simulated through path of the switch (Port 1 to Port 2 with $V_{\mathrm{c} 1}=-3 \mathrm{~V}$ and $V_{\mathrm{c} 2}=0 \mathrm{~V}$ ). The frequency responses of the switch are almost the same. The simulated results show 1-dB insertion loss at the center frequency and return losses better than $23 \mathrm{~dB}$. Fig. 10 shows a chip photograph of the SPDT switch. Fig. 11(a) shows the measured and simulated results of the through path of the switch. At $1-\mathrm{GHz}$ center frequency, the measured insertion loss is $1.5 \mathrm{~dB}$ and the return loss is better than $25 \mathrm{~dB}$. Fig. 11(b) shows the performance of the isolation path of the switch (Port 1 to Port 3 with $V_{\mathrm{c} 1}=-3 \mathrm{~V}$ and $V_{\mathrm{c} 2}=0 \mathrm{~V}$ ). The measured isolation is better than $27 \mathrm{~dB}$ at the center frequency. Fig. 11(c) is the return loss of Port 1, which shows better than $25-\mathrm{dB}$ measured return loss at the center frequency. The measured results are close to the simulated results when the frequency is below $1.5 \mathrm{GHz}$. The discrepancies between the simulation and measurement above $1.5 \mathrm{GHz}$ may be due to the inaccuracy of the parasitics of the packaged devices at higher frequencies.

The power compression of the SPDT switch in the center frequency $(1 \mathrm{GHz})$ is analyzed. The device parameters of the piecewise linear approximation are obtained and listed in Table I. In 


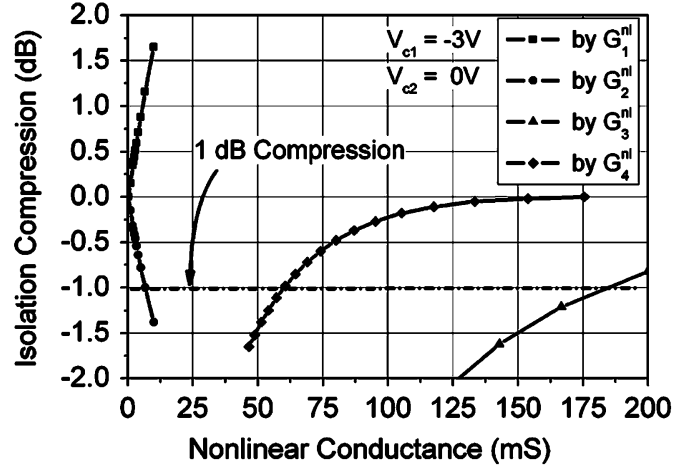

(a)

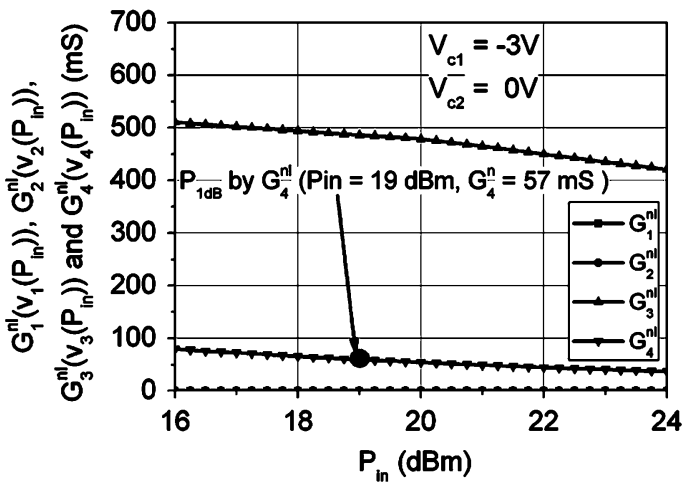

(b)

Fig. 14. (a) Compression of isolation from Port 3 to Port 1 isolation versus nonlinear conductances of 1-GHz SPDT hybrid switch. (b) Calculated nonlinear conductance versus input power $\left(P_{\text {in }}\right)$ at Port 3 of $1-\mathrm{GHz}$ SPDT hybrid switch.

TABLE II

Simplified Passive HEMT SMall-Signal Model and the Parameters OBTAINED FROM PIECEWISE LINEAR APPROXIMATION PARAMETERS FOR A TwO-FINGER 150-mm pHEMT DEVICE

\begin{tabular}{cc}
\hline \hline Parameters & Value \\
\hline$L_{\mathrm{d}}(\mathrm{pH})$ & 35.7 \\
$C_{\text {off }}(\mathrm{fF})$ & 46.97 \\
$G_{\text {on }}(\mathrm{S})$ & 0.145 \\
$G_{\text {off }}(\mathrm{S})$ & 0 \\
$L_{\mathrm{s}}(\mathrm{pH})$ & 1.35 \\
$R_{\mathrm{d}}(\Omega)$ & 2.36
\end{tabular}

\begin{tabular}{cc}
\hline \hline Parameters & Value \\
\hline$V_{\mathrm{x}}(\mathrm{V})$ & 2.35 \\
$V_{\mathrm{y} 1}(\mathrm{~V})$ & 0.1 \\
$V_{\mathrm{y} 2}(\mathrm{~V})$ & 0.35 \\
$V_{\mathrm{y} 1}(\mathrm{~V})$ & 0.4 \\
$V_{\mathrm{y} 2}(\mathrm{~V})$ & 1 \\
$G_{\mathrm{x}}(\mathrm{mS})$ & 80 \\
$G_{\mathrm{y} 1}(\mathrm{mS})$ & 140 \\
$G_{\mathrm{y} 2}(\mathrm{mS})$ & 80 \\
$G_{\mathrm{y} 3}(\mathrm{mS})$ & 12 \\
$G_{\mathrm{z} 2}(\mathrm{mS})$ & 69 \\
$G_{\mathrm{z} 3}(\mathrm{mS})$ & 30 \\
\hline \hline
\end{tabular}

the schematic for power analysis, shown in Fig. $12, \mathrm{M}_{1}$ and $\mathrm{M}_{2}$ are off-state transistors and $\mathrm{M}_{3}$ and $\mathrm{M}_{4}$ are on-state transistors.

The nonlinear channel conductance $\left(G_{1}^{\mathrm{nl}}-G_{4}^{\mathrm{nl}}\right)$ of each transistors are analyzed to predict the power compression. To find the relations between the insertion loss from Port 2 to Port 1 and each nonlinear conductance, the insertion losses are simulated with sweeping $G_{1}^{\mathrm{nl}}-G_{4}^{\mathrm{nl}}$, and are illustrated in Fig. 13(a). It can be observed that $G_{1}^{\mathrm{nl}}, G_{2}^{\mathrm{nl}}$, and $G_{3}^{\mathrm{nl}}$ are possible nonlinear elements to affect input $P_{1 \mathrm{~dB}}$ (they are 5,5 , and $73 \mathrm{mS}$, respectively).

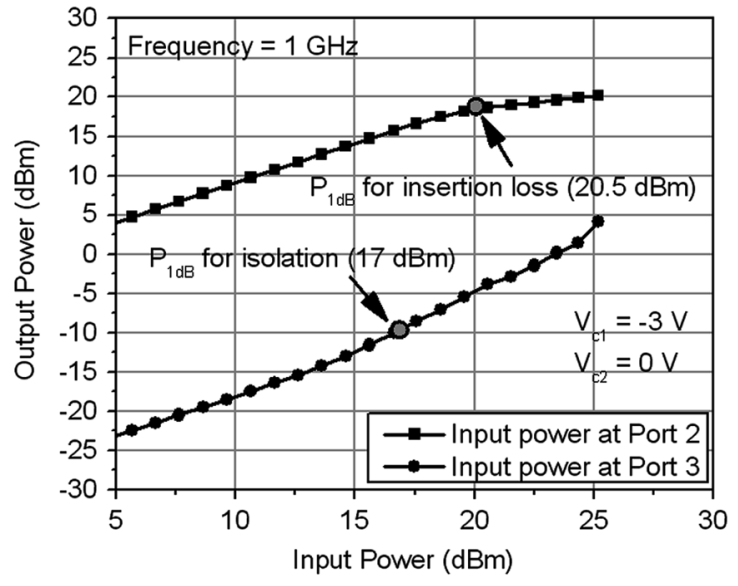

Fig. 15. Output power versus input power for insertion loss and isolation of the 1-GHz hybrid SPDT switch.

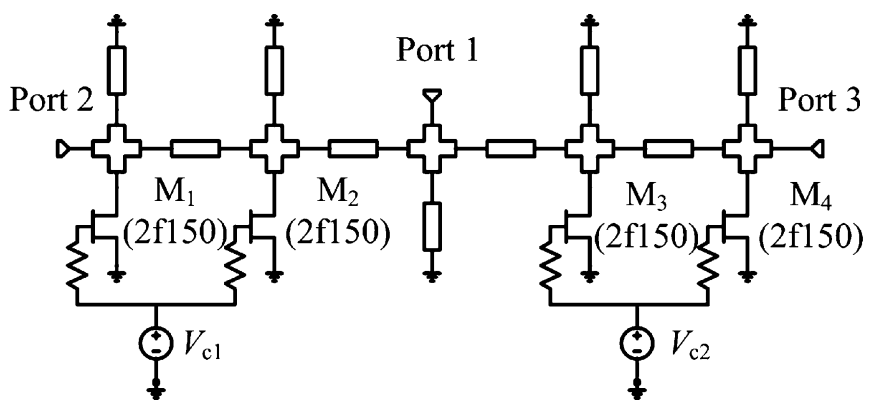

Fig. 16. Circuit schematic of the 60-GHz MMIC SPDT switch.

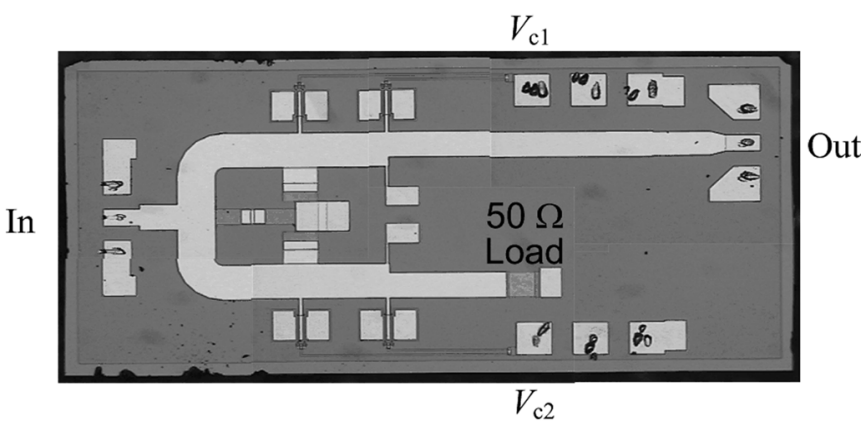

Fig. 17. $60-\mathrm{GHz}$ MMIC SPDT switch with chip size of $(2 \mathrm{~mm} \times 1 \mathrm{~mm})$.

The next step is to find an input power level such that the nonlinear conductance satisfies the condition of $1-\mathrm{dB}$ compression. The branch voltage of different power levels can be simulated by the linear simulation tool with the conductance satisfying the condition of 1-dB compression. Using (15) and (17), the nonlinear conductance under different input power $\left[G_{1}^{\mathrm{nl}}\left(v_{1}\left(P_{\text {in }}\right)\right)-G_{4}^{\mathrm{nl}}\left(v_{4}\left(P_{\text {in }}\right)\right)\right]$ are estimated. Fig. 13(b) shows the nonlinear conductance versus input power. It is observed that $P_{1 \mathrm{~dB}}$ is 19.9 and $22.7 \mathrm{dBm}$ by only considering $G_{2}^{\mathrm{nl}}$ and $G_{1}^{\text {nl }}$, respectively. The nonlinear conductance of $G_{3}^{\text {nl }}$ still does not decrease to $73 \mathrm{mS}$ for $24-\mathrm{dBm}$ input power. Thus, the actual input $P_{1 \mathrm{~dB}}$ of the SPDT switch is $19.9 \mathrm{dBm}$ (lower one between $19.9-22.7 \mathrm{dBm}$ ), and is determined by $G_{2}^{\mathrm{nl}}$. Therefore, the 1-dB compression of the insertion loss is dominated by $G_{2}^{\mathrm{nl}}$. 


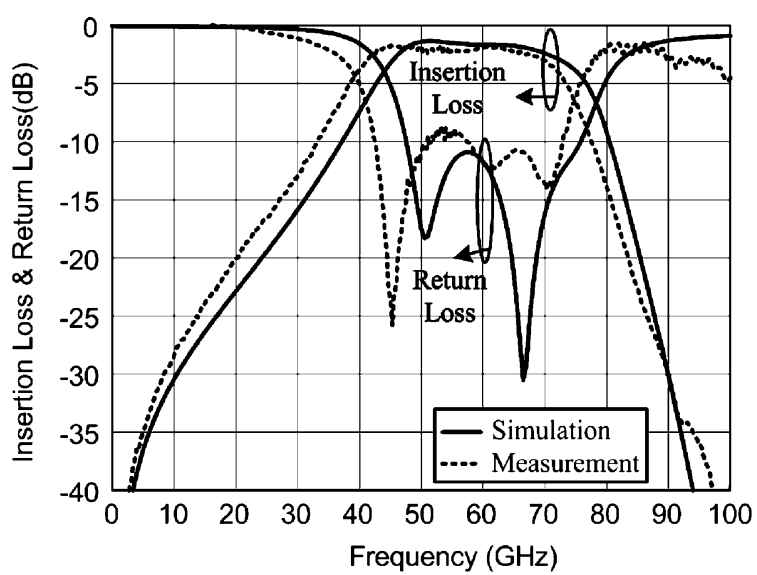

(a)

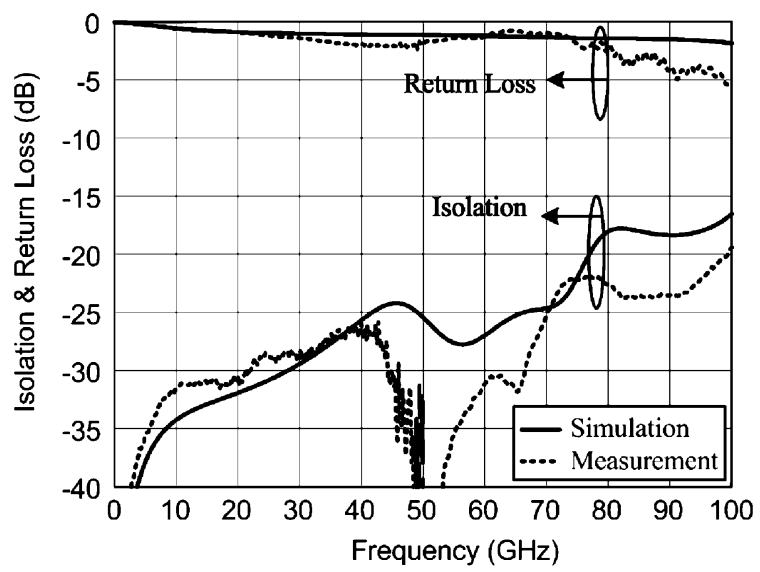

(b)

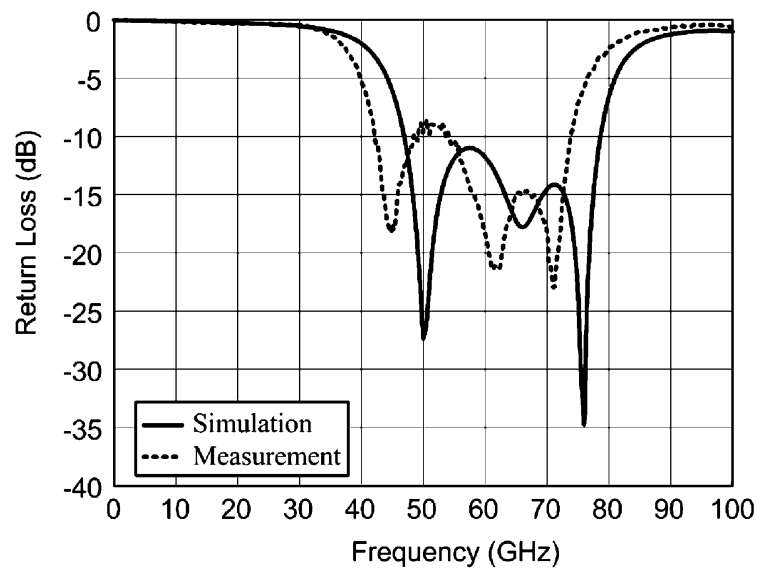

(c)

Fig. 18. Simulated and measured results of the 60-GHz MMIC SPDT switch. (a) Insertion loss and output return loss of the on-state switch. (b) Isolation and output return loss of the off-state switch. (c) Input return of the switch.

Regarding the isolation from Port 3 to Port 1, the 1-dB compression occurs when $G_{2}^{\mathrm{nl}}, G_{3}^{\mathrm{nl}}$, and $G_{4}^{\mathrm{nl}}$ are $6.6,166$ and $57 \mathrm{mS}$, respectively, and are shown in Fig. 14(a). The relation between the input power and nonlinear conductances are illustrated in Fig. 14(b). It can be observed that only $G_{4}^{\text {nl }}$ limits the isolation when the input power is below $24 \mathrm{dBm}$ and the predicted $P_{1 \mathrm{~dB}}$ is $19 \mathrm{dBm}$. Fig. 15 is the measured output power versus input power for insertion loss and isolation at center frequency

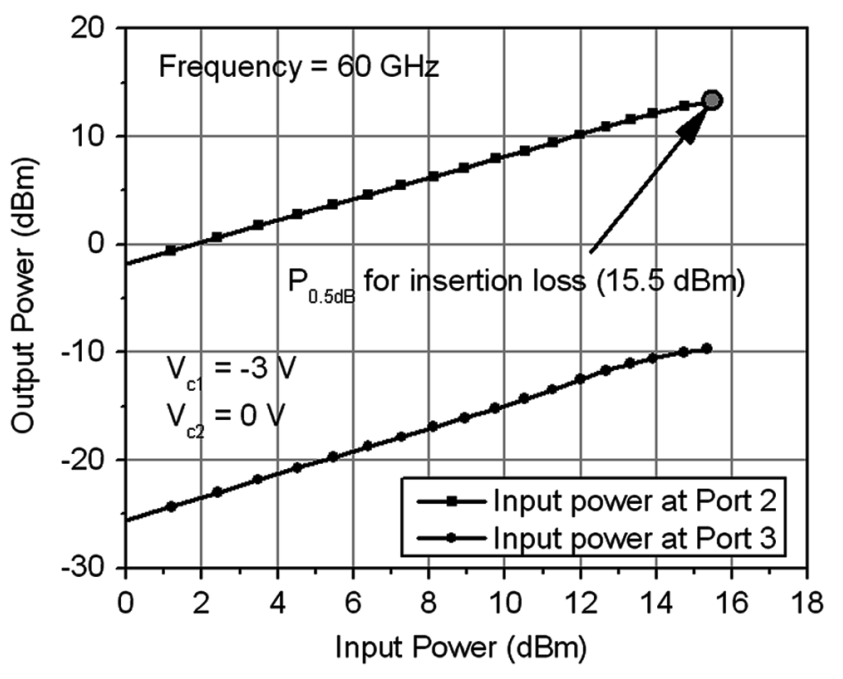

Fig. 19. Output power versus input power for insertion loss and isolation of the $60-\mathrm{GHz}$ MMIC SPDT switch.

TABLE III

COMPARISON BETWEEN THE SimULATEd AND MEASURED RESUltS

\begin{tabular}{|c|c|c|c|c|}
\hline Parameters & $\begin{array}{c}\text { Simu. of } \\
1-\mathrm{GHz} \\
\text { Switch }\end{array}$ & $\begin{array}{c}\text { Meas. of } \\
1-\mathrm{GHz} \\
\text { Switch }\end{array}$ & $\begin{array}{c}\text { Simu. of } \\
60-\mathrm{GHz} \\
\text { Switch }\end{array}$ & $\begin{array}{c}\text { Meas. of } \\
60-\mathrm{GHz} \\
\text { Switch }\end{array}$ \\
\hline $\begin{array}{l}\text { Insertion Loss }(\mathrm{dB}) \\
\text { @ center frequency }\end{array}$ & 1 & 1.5 & 2 & 2 \\
\hline $\begin{array}{l}\text { Isolation }(\mathrm{dB}) \\
\text { @ center frequency }\end{array}$ & 26 & 27 & 27 & 32 \\
\hline BWF $(\%)$ & 30 & 30 & 30 & 30 \\
\hline $\begin{array}{l}\text { Compression for } \\
\text { Insertion Loss }(\mathrm{dBm})\end{array}$ & $\begin{array}{l}19.9 \\
\left(P_{1 d B}\right)\end{array}$ & $\begin{array}{l}20.5 \\
\left(P_{1 d B}\right)\end{array}$ & $\begin{array}{l}16 \\
\left(\mathrm{P}_{0.5 \mathrm{~dB}}\right)\end{array}$ & $\begin{array}{l}15.3 \\
\left(\mathrm{P}_{0.5 \mathrm{~dB}}\right)\end{array}$ \\
\hline $\begin{array}{l}\text { Dominate Element for } \\
\text { Insertion Loss }\end{array}$ & $G_{2}^{n l}$ & & $G_{1}^{n l}$ & \\
\hline $\begin{array}{l}\text { Compression for } \\
\text { isolation }(\mathrm{dBm})\end{array}$ & $\begin{array}{l}19 \\
\left(\mathrm{P}_{1 \mathrm{~dB}}\right)\end{array}$ & $\begin{array}{l}17 \\
\left(\mathrm{P}_{1 \mathrm{~dB}}\right)\end{array}$ & $\begin{array}{l}19.2 \\
\left(\mathrm{P}_{1 \mathrm{~dB}}\right)\end{array}$ & N.A. \\
\hline $\begin{array}{l}\text { Dominate Element for } \\
\text { Isolation }\end{array}$ & $G_{4}^{n l}$ & & $G_{4}^{n l}$ & \\
\hline
\end{tabular}

( $1 \mathrm{GHz}$ ). The measured insertion loss $P_{1 \mathrm{~dB}}$ is $20.5 \mathrm{dBm}$ and isolation $P_{1 \mathrm{~dB}}$ is $187 \mathrm{dBm}$. Both of them are close to the predicted 19.9-dBm insertion loss $P_{1 \mathrm{~dB}}$ and $19-\mathrm{dBm}$ isolation $P_{1 \mathrm{~dB}}$, respectively. The input third order intercept point $\left(\mathrm{IIP}_{3}\right)$ at $1 \mathrm{GHz}$ with two tones of $100-\mathrm{kHz}$ offset was measured to be $25 \mathrm{dBm}$.

\section{B. 60-GHz MMIC SPDT Switch}

The process used in this design is WIN's $0.15-\mu \mathrm{m}$-high linearity AlGaAs/InGaAs/GaAs pseudomorphic HEMT (pHEMT) MMIC process [5]. In this design, the HEMT device of two fingers with total periphery of $150 \mu \mathrm{m}$ (2f150) was used. Following the simplified passive HEMT small-signal model in Fig. 6 and the piecewise linear approximation, the parameters of the HEMT device are listed in Table II.

The target frequency response of this switch is $60-\mathrm{GHz}$ center frequency, $30 \% \mathrm{FBW}$, and $0.01-\mathrm{dB}$ third-order equal ripple bandpass filter responses. With the target frequency response, the systematic synthesis approach in Section II is applied to determine the characteristic impedance and length of the transmission lines for the device with a total gatewidth of 
TABLE IV

Previously Published HEMT SPDT Switches AROund $60 \mathrm{GHz}$

\begin{tabular}{|c|c|c|c|c|c|c|}
\hline Author & Device & Approach & $\begin{array}{l}\text { Freq. Range } \\
\text { (GHz) }\end{array}$ & $\begin{array}{l}\text { Insertion } \\
\text { Loss }(\mathrm{dB})\end{array}$ & $\begin{array}{l}\text { Isolation } \\
\quad(\mathrm{dB})\end{array}$ & $\begin{array}{l}\text { Chip Size } \\
(\mathrm{mm} \times \mathrm{mm})\end{array}$ \\
\hline Z. M. Tsai Error! & $0.15 \mu \mathrm{m}$ & Traveling-wave concept & $15 \sim 135$ & $<6$ & $>20$ & $1.35 \times 0.5$ \\
\hline $\begin{array}{l}\text { Reference source not } \\
\text { found. }\end{array}$ & GaAs HEMT & & & & & \\
\hline $\begin{array}{l}\text { K.-Y. Lin et al.,Error! } \\
\text { Reference source not }\end{array}$ & $\begin{array}{c}0.15 \mu \mathrm{m} \\
\text { GaAs HEMT }\end{array}$ & Impedance transformation & $53 \sim 61$ & $<4$ & $>30$ & $2 \times 1$ \\
\hline $\begin{array}{l}\text { M. Madihian et al., } \\
\text { Error! Reference } \\
\text { source not found. }\end{array}$ & HJFET & Series resonant, shunt & $57-61$ & $3.9(\mathrm{Min})$ & 41 (Max) & $3.3 \times 1.7$ \\
\hline $\begin{array}{l}\text { K.-Y. Lin et al. Error! } \\
\text { Reference source not } \\
\text { found. }\end{array}$ & $\begin{array}{c}0.1 \mu \mathrm{m} \\
\text { GaAs HEMT }\end{array}$ & Traveling-wave concept & $15 \sim 80$ & $<3.6$ & $>25$ & $1.5 \times 1.5$ \\
\hline $\begin{array}{l}\text { K.-Y. Lin et al. Error! } \\
\text { Reference source not } \\
\text { found. }\end{array}$ & $\begin{array}{c}0.15 \mu \mathrm{m} \\
\text { GaAs HEMT }\end{array}$ & Traveling-wave concept & $\mathrm{DC} \sim 60$ & $<3$ & $>25$ & $1 \times 1$ \\
\hline $\begin{array}{l}\text { G. L. Lan et al. Error! } \\
\text { Reference source not } \\
\text { found. }\end{array}$ & $\begin{array}{c}0.15 \mu \mathrm{m} \\
\text { GaAs HEMT }\end{array}$ & Resonant, series & $54 \sim 64$ & $<3.2$ & $>23$ & $0.8 \times 2.45$ \\
\hline $\begin{array}{l}\text { J. Kim et al., Error! } \\
\text { Reference source not } \\
\text { found. }\end{array}$ & $\begin{array}{c}0.15 \mu \mathrm{m} \\
\text { GaaAs HEMT }\end{array}$ & $\begin{array}{l}\text { FET-integrated transmission } \\
\text { line structure }\end{array}$ & $40 \sim 85$ & $<2$ & $>30$ & $1.45 \times 1$ \\
\hline
\end{tabular}

$150 \mu \mathrm{m}$. Fig. 16 shows the complete schematic diagram of the 60-GHz MMIC SPDT switch. The discontinuous junctions and parasitic effects of the transmission lines are all characterized with the Sonnet electromagnetic simulation tool [6]. Fig. 17 shows a chip photograph of the SPDT switch with a chip size of $2 \mathrm{~mm} \times 1 \mathrm{~mm}$.

The chip was measured via an on-wafer test. Since that two RF ground-signal-ground (GSG) probes cannot be placed on the same side of the chip for an on-wafer test, one of the output ports is terminated with an on-chip $50-\Omega$ load. In order to measure the complete frequency-response shape of this SPDT switch, three different test sets for different bands (dc to $50 \mathrm{GHz}, V$-band, and $W$-band) are used. Fig. 18(a) illustrates the measured and simulated results of the on-state switch. At the center frequency of $60 \mathrm{GHz}$, the measured insertion loss is $2.5 \mathrm{~dB}$ and the return loss is better than $10 \mathrm{~dB}$. Fig. 18(b) shows the off-state switch performance. The measured isolation is better than $30 \mathrm{~dB}$ at center frequency. Fig. 18(c) shows the return loss of the input port, which shows better than $10-\mathrm{dB}$ measured return loss at center frequency. From 45 to $65 \mathrm{GHz}$, the MMIC SPDT switch has an insertion loss, isolation, and return loss better than $2.2,30$, and $8 \mathrm{~dB}$, respectively. They all reasonably agree with the simulated results.

Fig. 19 illustrates the measured output power versus input power for insertion loss and isolation. Due to the power limitation of the $60-\mathrm{GHz}$ signal source, we can only measure $0.5-\mathrm{dB}$ compression of the insertion loss when the input power is $15.3 \mathrm{dBm}$. For the isolation, the power compression does not occur when the input power is $15.3 \mathrm{dBm}$. Using the same analysis procedure in the $1-\mathrm{GHz}$ hybrid SPDT switch, the conductances for the $0.5-\mathrm{dB}$ compression of insertion loss are $1.1 \mathrm{mS}$ for $G_{1}^{\mathrm{nl}}, 1.35 \mathrm{mS}$ for $G_{2}^{\mathrm{nl}}$, or $43 \mathrm{mS}$ for $G_{3}^{\mathrm{nl}}$ by sweeping the nonlinear conductance, and then the nonlinear conductance can be evaluated by (15) and (17) with the swing voltage of the input power at port 2. It is also observed that the dominant component is $G_{1}^{\mathrm{nl}}$ at input power of $16 \mathrm{dBm}$. Regarding isola- tion, $G_{2}^{\mathrm{nl}}=1.22 \mathrm{mS}, G_{3}^{\mathrm{nl}}=77 \mathrm{mS}$, or $G_{4}^{\mathrm{nl}}=83 \mathrm{mS}$ are the conductances for the $0.5-\mathrm{dB}$ compression point of isolation. Thus, the $0.5-\mathrm{dB}$ compression of isolation is estimated to be $19.2 \mathrm{dBm}$ and the dominate element is $G_{4}^{\mathrm{nl}}$, although we cannot measure this power level.

Table III lists the comparison between the simulated and measured results of the 1-GHz hybrid and the 60-GHz MMIC SPDT switches. The dominate components for the power compression are determined. The simulated results are close to the measured results; therefore, the design approach of the FIS and the predictions of the power performance are verified.

Table IV lists the published HEMT switch around $60 \mathrm{GHz}$ and compares it with our SPDT FIS. The 2.5-dB insertion loss in the passband is the best result, except for [11], which shows that no tradeoffs is required when integrating the filter function into a switch.

\section{CONCLUSION}

In this paper, the concept of the FIS, which integrates the quarter-wavelength bandpass filter into an SPDT, has been expanded from the SPST switch to the SPDT switch. The systematic design approach is presented so that the design parameters of the SPDT switch can be determined by applying the filter synthesis. A more general analysis to predict the power compression has also been described. The experimental circuits of hybrid 1- and 60-GHz MMIC SPDT switches both have 30\% FBW, and a $0.1-\mathrm{dB}$ equal ripple filter frequency response was built and measured. The 1-GHz switch exhibits 1.5-dB insertion loss and 27-dB isolation at center frequency, while the $V$-band switch has 2-dB insertion loss and 32-dB isolation at center frequency. For the 1-GHz SPDT switch, the measured $P_{1 \mathrm{~dB}}$ for the insertion loss is $20.5 \mathrm{dBm}$ and the isolation $P_{1 \mathrm{~dB}}$ is $17 \mathrm{dBm}$. For the $60-\mathrm{GHz}$ SPDT switch, the insertion loss $P_{0.5 \mathrm{~B}}$ is $15.3 \mathrm{dBm}$. The measured data are close to the predicted results. The method also provides a simple and precise way to obtain the power compression point and the dominant components without generating 
nonlinear models and nonlinear simulation tools, which is useful to design for the power performance of SPDT switches.

\section{ACKNOWLEDGMENT}

The authors would like to thank to Prof. G. D. Vendelin, National Central University, Chung Li, Taiwan, R.O.C., for his advice and review.

\section{REFERENCES}

[1] T.-S. Martin, F. Wang, and K. Chang, "Theoretical and experimental Investigation of novel varactor-tuned switchable microstrip ring resonator circuits," IEEE Trans. Microw. Theory Tech., vol. 36, no. 12, pp. 1733-1739, Dec. 1988.

[2] J. Lee, Z.-M. Tsai, and H. Wang, "A bandpass filter-integrated switch using field-effect transistors and its power analysis," in IEEE MTT-S Int. Microw. Symp. Dig., San Francisco, CA, 2006, pp. 768-771.

[3] S. F. Chang, W.-L. Chen, J.-L. Chen, H.-W. Kung, and H.-Z. Hsu, "New millimeter-wave MMIC switch design using the image-filter synthesis method," IEEE Microw. Wireless Compon. Lett., vol. 14, no. 3 , pp. 103-105, Mar. 2004.

[4] K.-Y. Lin, W.-H. Tu, P.-Y. Chen, H.-Y. Chang, H. Wang, and R.-B. Wu, "Millimeter-wave MMIC passive HEMT switches using travelingwave concept," IEEE Trans. Microw. Theory Tech., vol. 52, no. 8, pp. 1798-1808, Aug. 2004.

[5] "WIN Semiconductors GaAs 0.15 WIN Inc., Taipei, Taiwan, R.O.C., 2003.

[6] “Sonnet User's Manual," Sonnet Softw. Inc., Liverpool, NY, 1998.

[7] Z.-M. Tsai, M.-C. Yeh, H.-Y. Chang, M.-F. Lei, K.-Y. Lin, C.-S. Lin, and $\mathrm{H}$. Wang, "FET-integrated CPW and the application in filter synthesis design method on traveling-wave switch above $100 \mathrm{GHz}$," IEEE Trans. Microw. Theory Tech., vol. 54, no. 5, pp. 2090-2097, May 2006.

[8] K.-Y. Lin, Y.-J. Wang, D.-C. Niu, and H. Wang, "Millimeter-wave MMIC single-pole-double-throw passive HEMT switches using impedance-transformation networks," IEEE Trans. Microw. Theory Tech., vol. 51, no. 4, pp. 1076-1085, Apr. 2003.

[9] M. Madihian, L. Desclos, K. Maruhashi, K. Onda, and M. Kuzuhara, "A sub-nanosecond resonant-type monolithic T/R switch for millimeter-wave systems applications," IEEE Trans. Microw. Theory Tech., vol. 46, no. 7, pp. 1016-1019, Jul. 1998.

[10] G. L. Lan, D. L. Dunn, J. C. Chen, C. K. Pao, and D. C. Wang, "A high performance $V$-band monolithic FET transmit-receive switch," in IEEE Microw. Millimeter-Wave Monolithic Circuits Symp. Dig., New York, NY, Jun. 1988, pp. 99-101.

[11] J. Kim, W. Ko, S.-H. Kim, J. Jeong, and Y. Kwon, "A high-performance 40-85 GHz MMIC SPDT switch using FET-integrated transmission line structure," IEEE Microw. Wireless Compon. Lett., vol. 13 , no. 12, pp. 505-507, Dec. 2003.

[12] S. F. Chao, C.-H. Wu, Z.-M. Tsai, H. Wang, and C.-H. Chen, "Electronically switchable bandpass filters using loaded stepped-impedance resonators," IEEE Trans. Microw. Theory Tech., vol. 54, no. 12, pp. 4193-4201, Dec. 2006

[13] "NEC hetero junction field effect transistors," NEC Inc., Kanagawa, Japan, NE32584C Data Sheet, 1997.

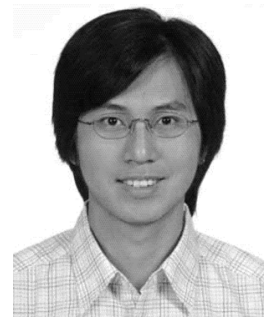

Zuo-Min Tsai (S'01-M'06) was born in Mailo, Taiwan, R.O.C., in 1979. He received the B.S. degree in electronic engineering and Ph.D. degree in communication engineering from National Taiwan University, Taipei, Taiwan, R.O.C., in 2001 and 2006, respectively.

$\mathrm{He}$ is currently a Post-Doctoral Research Fellow with the Graduate Institute of Communication Engineering, National Taiwan University. His research interests are the theory of microwave or millimeterwave circuits.

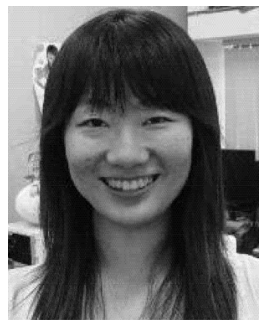

Yu-Sian Jiang was born in Kaoshiung, Taiwan, R.O.C., in 1984. She received the B.S. degree in electrical engineering from National Taiwan University, Taipei, Taiwan, R.O.C., in 2006, and is currently working toward the M.S. degree at National Taiwan University.

She is currently with the Graduate Institute of Communication Engineering, National Taiwan University. Her research interests include monolithic microwave/millimeter-wave circuit design.

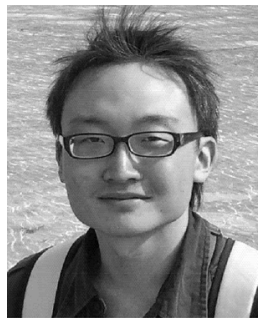

Jeffrey Lee (S'07) was born in Buffalo, NY, in 1984. He received the B.S. degree in electrical engineering from National Taiwan University, Taipei, Taiwan, R.O.C., in 2006, and is currently working toward the Master degree at National Taiwan University.

His research interests include the design of MMICs and the theory of microwave circuits.

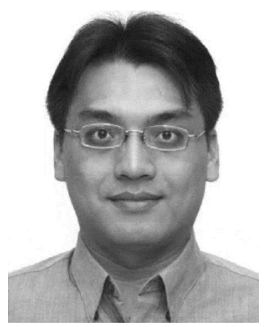

Kun-You Lin (S'00-M'04) was born in Taipei, Taiwan, R.O.C., in 1975. He received the B.S. degree in communication engineering from National Chiao Tung University, Hsinchu, Taiwan, R.O.C., in 1998, and the Ph.D. degree in communication engineering from National Taiwan University, Taipei, Taiwan, R.O.C., in 2003.

From August 2003 to March 2005, he was a Post-Doctoral Research Fellow with the Graduate Institute of Communication Engineering, National Taiwan University. From May 2005 to July 2006, he was an Advanced Engineer with the Sunplus Technology Company Ltd., Hsin-Chu, Taiwan, R.O.C. In July 2006, he joined the faculty of the Department of Electrical Engineering and the Graduate Institute of Communication Engineering, National Taiwan University, as an Assistant Professor. His research interests include the design and analysis of microwave/RF circuits.

Dr. Lin is a member of Phi Tau Phi.

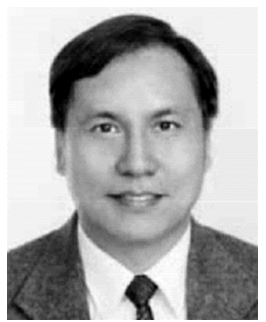

Huei Wang (''83-M'87-SM'95-F'06) was born in Tainan, Taiwan, R.O.C., on March 9, 1958. He received the B.S. degree in electrical engineering from National Taiwan University, Taipei, Taiwan, R.O.C., in 1980, and the M.S. and Ph.D. degrees in electrical engineering from Michigan State University, East Lansing, in 1984 and 1987, respectively.

During his graduate study, he was engaged in research on theoretical and numerical analysis of electromagnetic radiation and scattering problems. He was also involved in the development of microwave remote detecting/sensing systems. In 1987, he joined the Electronic Systems and Technology Division, TRW Inc. He has been an MTS and Staff Engineer responsible for MMIC modeling of computer-aided design (CAD) tools, MMIC testing evaluation, and design and became the Senior Section Manager of the Millimeter-Wave (MMW) Sensor Product Section, RF Product Center. In 1993, he visited the Institute of Electronics, National Chiao-Tung University, Hsinchu, Taiwan, R.O.C., to teach MMIC related topics. In 1994, he returned to TRW Inc. In February 1998, he joined the faculty of the Department of Electrical Engineering, National Taiwan University, as a Professor. He is currently the Director of the Graduate Institute of Communication Engineering, National Taiwan University.

Dr. Wang is a member of Phi Kappa Phi and Tau Beta Pi. He was the recipient of the Distinguished Research Award of National Science Council, R.O.C. (2003-2006). In 2005, he was elected as the first Richard M. Hong Endowed Chair Professor of National Taiwan University. He has been appointed an IEEE Distinguished Microwave Lecturer for the 2007-2009 term. 